\title{
Research on the Evolution and Classification of Digital Learning Resources
}

\author{
Jiayang Wang ${ }^{1, \mathrm{a}}$, Meng $\operatorname{Han}^{1, \mathrm{~b}}$ and Wanwan Wang ${ }^{1, \mathrm{c}}$ \\ ${ }^{I}$ Educational Technology College/Northwest Normal University, Lanzhou, Gansu, China \\ 3978998932@qq.com, ${ }^{b}$ hanmeng9494@163.com, ${ }^{c} 1073382751 @ q q . c o m$
}

\begin{abstract} learning resources and types of digital learning resources.

\section{INTRODUCTION}

With the advent of globalization, information age and knowledge society, digital survivability has become an indispensable ability for students, and digital learning is an important learning method for digital survival. Digital learning resources are not only the key to digital learning, but also one of the research hot topic in the field of education. It is basis for the application of digital learning resources that accurately grasp the connotation of digital learning resources and clarify its type.
\end{abstract}

With the maturity of new technologies such as big data, virtual reality and artificial intelligence, the types of digital learning resources are constantly enriched, The current hot topic of academic circles is how to systematically classify digital learning resources, and then provide guidance for exploring the construction, supply and application of different types of digital learning resources. This study cuts into the research of foreign AECT on digital learning resources and research results of domestic digital learning resources. At the same time, it combines the typical information technology in the education field, and summarizes the classification framework of digital learning resources, and uses the compass principle as a guide to summarize the digital learning resource classification framework and divide the digital learning resources. The framework divides digital learning resources into six categories: basic knowledge classes, auxiliary extension classes, tool software classes, network platform classes, virtual reality classes, and generative learning resources, and proposes a digital learning resource compass from three dimensions: discipline, acquisition mode of digital

Keywords: digital learning resources, information technology, connotation, classification

\section{THE PAST: RESEARCH ON THE CONNOTATION AND CLASSIFICATION OF DIGITAL LEARNING RESOURCES}

Literature is the main carrier of knowledge and contains rich meaning ${ }^{[1]}$. To understand the process of the change of learning resources, it is necessary to make a systematic analysis of the literature of the former digital learning resources. Up to now, research on digital learning resources has covered many issues such as connotation, classification, development and application. The specific discussion has shifted from the initial focus on the development and construction of learning resources to the sharing and application of learning resources, and in recent years, academic researches on learning resources mainly focus on how to support students' learning.

The main steps of literature research include defining research problems, confirming keywords and research strategies, screening and evaluating research, data extraction and data integration. The research question in this study is what is the connotation of digital learning resources? What types are included of digital learning resources? Due to the academic community don't have clearly divide of concepts about the "digital learning resources" and "E-learning resources", this study uses "learning resources" as the key word to obtain a wider range of literature. In order to avoid bias in the conclusions of the literature, this study expands the literature search database into three databases: "Full Text of Chinese Journals", "Full Text of Chinese Doctoral Dissertation" and "Full Text of Chinese Excellent Master's Thesis", among which "Chinese Journal Full Text" focuses on dual-core journals, (Core Journal and Chinese Social Science Citation Index "CSSCI" Journal), and the time span is from January 1, 1997 to December 30, 2018.

A total of 785 "learning resources" documents were retrieved from three databases based on "CNKI" (China National Knowledge Infrastructure) . Among them, there are 438 journal theses ( 7 articles have been removed from meetings, notices and other documents.), 332 excellent master's dissertations, and 15 doctoral dissertations. The following results were obtained by analyzing the literature time, subject, and the like.

\subsection{The Year Analysis of Learning Resource Research}

The development trend of learning resources can be understood through the statistical analysis of literature publication time, as shown in Figure 1. The first document on learning resources in China was "learning resources and learning process -- the main object of educational technology practice and research" written by professor ZHANG Wei-Min of the department of educational information technology, east China normal university in 1997, and the article expounds that to do a good job in teaching not only needs to study how teachers teach, but also needs to pay attention to students' learning. According to the number of 
literatures in each year, the study on learning resources in China was in the exploration stage from 1997 to 2004, during which academic circles paid less attention to learning resources, especially before 2001, both literatures were inspirations and interpretations on the definition of AECT education technology in the United States. From 2005 to 2012, the study of learning resources in China entered a stage of rapid development, in this stage, there will be a certain amount of literature every year and the research content is more extensive. From 2013 to now, the research on learning resources in China has entered a superheating stage, with 86 related literatures on learning resources in 2013.

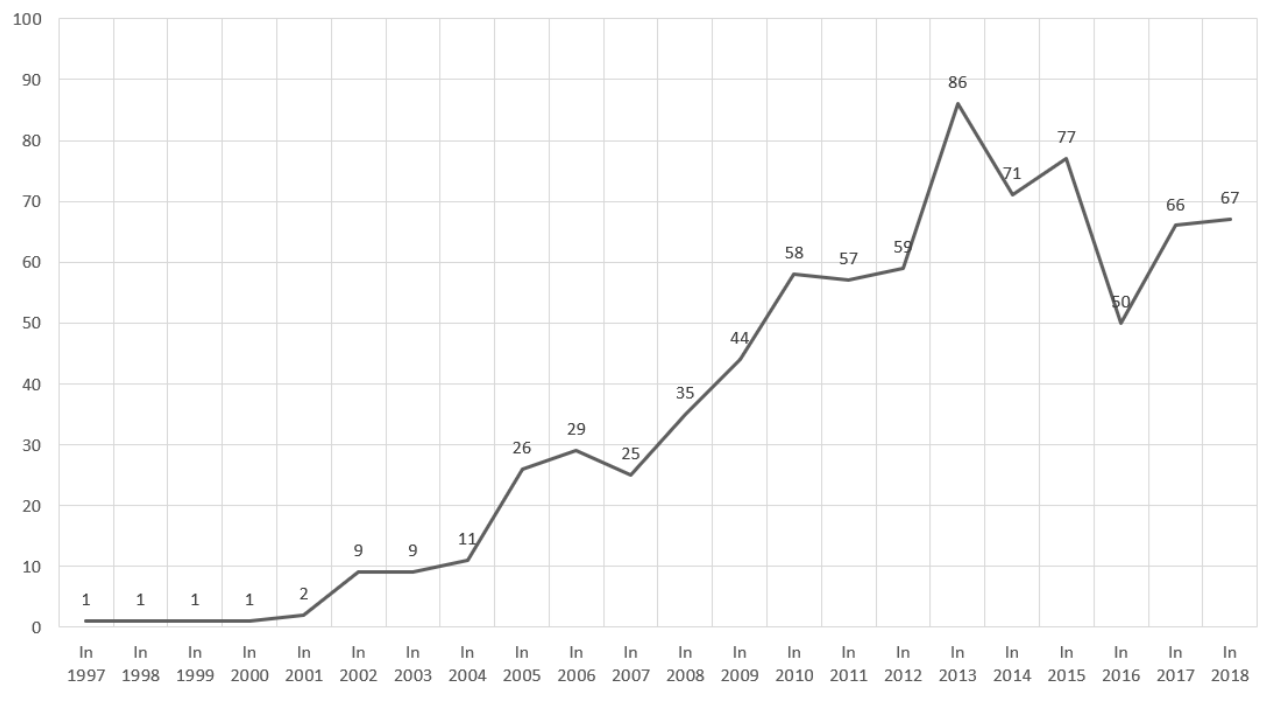

Figure 1 Year distribution map of learning resources literature

\subsection{The Subject Analysis of Learning Resource Literature}

The distribution of literature topics of learning resources is shown in Figure 2. It can be seen from the distribution of literature topics in China that the focus of learning resources is mainly on learners, mobile learning resources, mobile learning, digital learning resources, network learning resources, learning resources recommendation and other aspects. The number of relevant literatures on learner learning resources reached 201, and the number of articles on mobile learning resources, mobile learning and digital learning resources all exceeded 100.

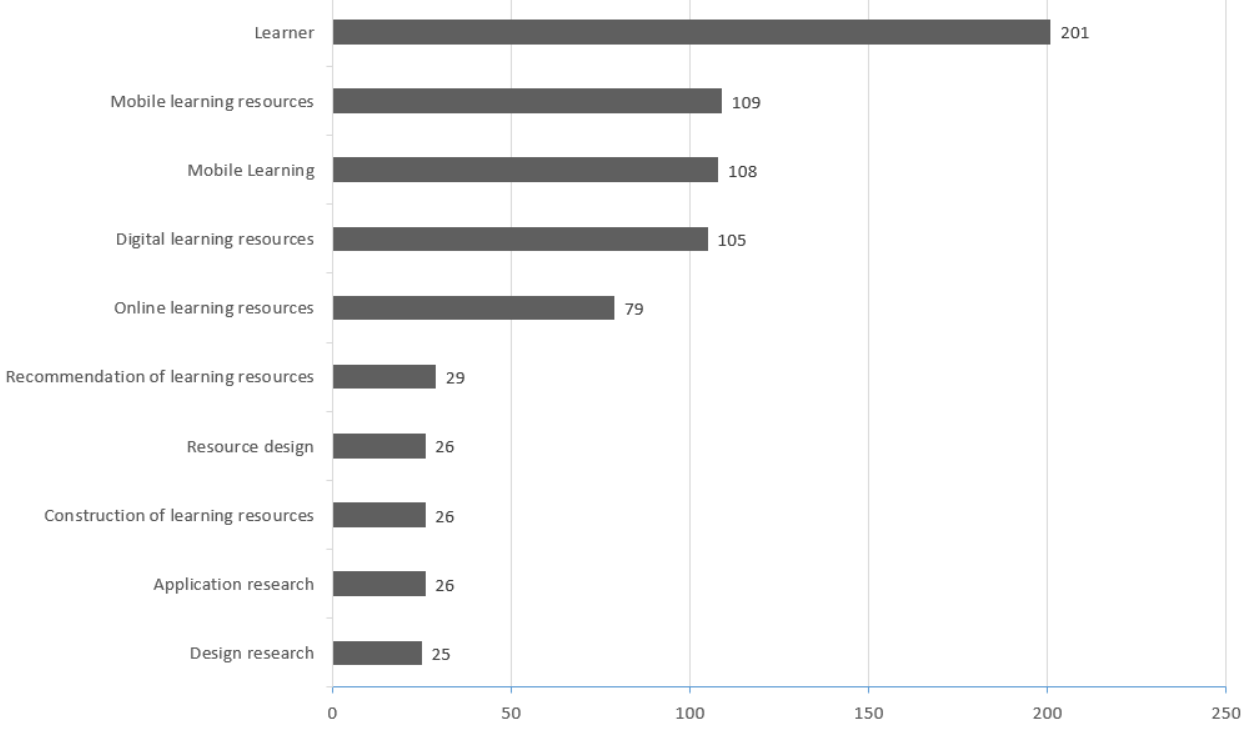

Figure 2 Learning resources literature topic map

\section{NOW: THE CONNOTATION AND CLASSIFICATION OF DIGITAL LEARNING RESOURCES}

In modern time, the development of information technology is changing with each passing day, and the development and application of multimedia technology has achieved fruitful results. The technologies of mobile Internet, Internet of Things, big data, cloud computing, virtual reality, artificial intelligence are becoming more and more mature, personal terminal devices such as computers are popular in the home, 
promoting teaching, and such resources are often referred to

and portable devices such as tablets, e-readers (Kindle, iPad, etc.) and smart phones are widely used in work, study and life. Information technology is the condition for the development and utilization of digital educational resources, with the development of information technology, more and more digital learning resources are being developed and applied, and different information technologies and their cross-integration will have different influences on the manifestation and function of digital education resources ${ }^{[2]}$.

\subsection{The Connotation of Digital Learning Resources}

Connotation refers to the specific attribute and essential attribute of the thing reflected by the concept, that is, the specific attribute of the object and the reflection of the essential attribute in the concept. However, different research perspectives will lead to different definitions of the same object. This study explores the connotation of digital learning resources from the two dimensions of the American Association for Educational Technology and Communication (AECT) and other viewpoints in academia.

In 1972, the American Association for Educational Technology and Communication (AECT) elaborated on learning resources: Some resources are designed for specific learning objectives, so these resources can play a role in as "teaching materials or teaching resources"; in addition, there are some resources that exist in nature and our daily lives, but these resources can also be discovered, developed, and applied to teaching, and these resources are called "real world resources." In the definition of educational technology in 1977, resources were not directly stated, but various learning resources were listed in the explanation, including people, materials and devices, which emphasized that learning resources were not limited to media. In the definition of resources in 1994: Learning resources are anything that helps individuals learn and operate effectively. The definition of resources in 2004: resources are people, tools, technology, and materials designed to help learners ${ }^{[3]}$.It can be seen that the field of educational technology has paid attention to students for a long time. After the 1960s, the new actors represented by Skinner's "Operational Condition" began to pay attention to how students' behaviors were changed and corrected, that is, emphasizing how learning is produced, the Association of Educational Technology and Communication (AECT) emphasizes the connotation of learning resources from the early on teaching media (teaching materials) to the attention of people, materials, equipment and media, and is currently focused on promoting learner learning. The academic circles has proposed more definitions of digital learning resources, as shown in Table 1: 
Table 1 Comparison of the connotation of digital learning resources

\begin{tabular}{|c|}
\hline Content \\
\hline $\begin{array}{l}\text { Refers to those people, materials, tools, facilities, activities etc., that students } \\
\text { can make meaningful connections to }{ }^{[4]} \text {. }\end{array}$ \\
\hline $\begin{array}{l}\text { A series of internal and external supporting conditions that can influence and } \\
\text { change people's cognitive structure or promote the change of people's } \\
\text { cognitive structure }{ }^{[5]} \text {. }\end{array}$ \\
\hline $\begin{array}{l}\text { A multimedia material that can be processed digitally and run in a multimedia } \\
\text { computer network environment. It enables digital learning by motivating }\end{array}$ \\
\hline
\end{tabular}
creativity $^{[6]}$.

Anything that enables learners to gain knowledge or accelerate the speed and efficiency of learning can be called resources for learning ${ }^{[7]}$.

SHEN Shu-Sheng

LI Ke-Dong

CAO Mei

Refers to information, technology, and the environment that can be provided to learners to help and facilitate learners' learning ${ }^{[8]}$.

ZHANG Jun-Wei

All hardware devices, software tools, knowledge information, and application services that have a meaningful connection to the teaching process ${ }^{[9]}$.

Refers to the source of funding for learning, including all kinds of software materials and hardware systems that support the teaching process, and broadly includes all the people, finances, things etc., that can serve the purpose of teaching ${ }^{[10]}$.

Digital learning resources refer to multimedia information resources that can be learned and arranged according to the characteristics of learners, can be operated on a multimedia computer or in a network environment, and can be learned independently or cooperatively by learners and can be widely shared ${ }^{[11]}$.

The sum of all the elements that can be used by learners in the learning process, including information, materials, equipment, personnel, places, $\operatorname{etc}^{[12]}$.

Digital learning resources refer to the sum of various learning resources that can be utilized by computer networks, specifically, it refers to all the learning resources that use electronic data to store text, image, sound, video, animation and other forms of information in optical, magnetic, flash memory and other non-paper media carriers, and transmit or reproduce them through the network, computer or terminal ${ }^{[13]}$.
Digital learning resources are an integral part of learning resources, the understanding of learning resources is a spiraling process, and the earliest learning resources of human beings are only language and life practice, the invention of text and printing expands learning resources into books, after the $1920 \mathrm{~s}$, due to the development of science and technology and industrial modernization, learning resources include new media such as photography, slides, movies and radio broadcasts, after the 1980s, learning resources included support systems and teaching materials and environment, not just equipment and materials for the teaching process, including people, budgets and facilities, and even anything that can help individuals learn and operate effectively. Due to the different professional backgrounds, research perspectives, research scope and ages, different scholars have different understandings of digital learning resources. Starting from the nature and function of digital learning resources, this study defines digital learning resources as: using multimedia technology, Internet technology, software development technology, virtual reality technology and artificial intelligence technology to design and develop information technology, which can support 
students to learn independently, cooperative learning, inquiry learning, and hybrid learning, and a sequence of binary digits that can be identified, accessed, and processed by a computer consisting of 0,1 .

\subsection{The Classification of Digital Learning Resource}

Classification is one of the effective means for people to understand things and it is a logical method to distinguish and organize things, at the same time, it refers to the process of integrating various things into categories based on their essential attributes or other significant attributes.

Table 2 Comparison table of digital learning resources classification
Classification needs to find out common things from complicated things and classify them separately, and with the systematic study of classification methods and accumulation on the theoretical level, classification has gradually developed into a basic method of natural science research. With the continuous development of information technology, new digital learning resources keep emerging, and it is more profound, more general and more comprehensive for people to understand digital learning resources that digital learning resources are classified systematically. Academic circles classification of digital learning resources is shown in Table 2 .

Content Representative Scholar Years

Material teaching resources, network course library, educational resource management system, general remote teaching system support platform.

\author{
Technical norms for \\ resources construction \\ of modern distance \\ education (trial)
}

In 2000

Digital video, digital audio, multimedia software, CD-ROM, website, email, online learning management system, computer simulation, online discussion, data files, database.

LI Ke-Dong

In 2001

"Teaching-oriented" digital learning resources: courseware, case-based; "learning-based" digital learning resources: multimedia materials, literature materials, information learning tools.

HE Ke-Kang

Electronic books, electronic journals, online data sequences, virtual libraries, encyclopedias, education network communication newsgroups and virtual software eight categories.

Hardware resources, software resources, human resources.

Multimedia and networked digital education resources, generated and open digital education resources, virtual learning resource environment, intelligent learning resource environment.

GUO Shao-Qing

Classification object and classification basis are two core elements of classification. Object classification of digital learning resources, this study refers to the application in the teaching and learning activities, teachers' teaching and students' learning by service for the purpose, to consisting of 0 , 1 , the computer can identify, access and processing sequence of binary digits form of courseware, curriculum resources, material, tools, platform, and a collection of social software and other kinds of resources; The main purpose of digitized learning resources is the classification basis of digitized learning resources in this study. Finally, digitized learning resources are divided into four dimensions, including six types.

\subsubsection{Basic Digital Learning Resources}

(1) Basic knowledge learning resources

It mainly refers to the digital education resources for teachers and students, which are closely related to education teaching and knowledge imparting and are matched with the national curriculum standards and unified textbooks, including teaching courseware, curriculum plan, after-class exercises, e-books, learning resource package and 
micro-video and so on. Such resources do not have high technical requirements, but they must be authoritative, scientific, educational and accurate, and they are necessary resources for the development of formal school education or informal teaching and learning activities in the field of basic education in China.

(2) Auxiliary development learning resources

It mainly refers to digital education resources for the public to popularize knowledge related to social science and natural science such as culture, history, science and technology, geography, biology, physics and so on, especially special websites, digital museums, digital science and technology museums, etc. This kind of resources is helpful to broaden the vision of the public and is also the main source of knowledge for students in the field of basic education.

(3) Generative learning resources

It mainly refers to the generative basic education resources that teachers independently develop and apply in the process of front-line education and teaching activities. Although such resources are relatively scattered and lack of systematicness, the explicit and rational display of teachers' teaching wisdom can be a good reference for teachers to improve their teaching practice and professional development, as well as an important supplement to the first two types of resources.

\subsubsection{Tools Software Learning Resources}

It refers to learning resources that can effectively support, promote and evaluate learning, improve teaching and learning performance, and facilitate teachers and students to design various teaching and learning activities. This kind of resource has high technical content, including discipline software that supports knowledge management, learning evaluation, distance learning and other functions, and digital learning resources that support virtual simulation system and other technical tools.

\subsubsection{Network Platform Class Digital Learning Resources}

It refers to the platform resources for teachers and students to create teaching and learning space and innovate all kinds of teaching activities. This kind of resource has complex structure design and high technical content, and can help teachers improve the teaching effect, help students comprehensively record data and support analysis. Digital education resources including teaching interactive platform, network resource platform, network course platform, learning space and maker space are developed based on the actual needs of front-line education and teaching.

\subsubsection{Virtual Reality Learning Resources}

Sherman and Jenkins define virtual reality with "Intensive", "Interactive", "Immersive", "Illustrative" and "Intuitive", which is referred to by the academic community as "5I"[14]. Virtual reality learning resources can reflect the real situation and interact with the virtual world through wearable devices. This experience can promote learners' knowledge acquisition and meet their personal needs. For example, it presents resources of the universe, celestial bodies, cells and molecular models, cross-space and time-space reproduction resources of historical events, exotic landscapes and ancient buildings, experience resources of microscopic particles, life systems and ecosystems, and virtual experimental environment of explosion experiments, toxic and dangerous goods.

\section{THE FUTURE: THE CLASSIFICATION FRAMEWORK OF 3D DIGITAL LEARNING RESOURCES}

Information technology is a necessary condition for the development and application of digitized learning resources, and different information technologies can influence digitized learning resources from their forms and functions. Based on the essential properties of digital learning resources, this study proposes a classification framework of 3D digital learning resources by combining its multi-dimension and constantly enriching characteristics resource classification framework.

\subsection{Development of Information Technology}

The development of information technology has a revolutionary impact on education. It can not only change people's knowledge skills and values, but also change the methods and means needed to cultivate people. Defining typical information technology is conducive to a comprehensive understanding of digital learning resources. The typical information technology is sorted out as shown in Table 3: 
Table 3 Typical information technology in the field of education

\begin{tabular}{|c|c|c|c|}
\hline $\begin{array}{l}\text { Information } \\
\text { Technology }\end{array}$ & \multicolumn{2}{|c|}{ Connotation } & Learning Resources \\
\hline $\begin{array}{l}\text { Multimedia } \\
\text { technology }\end{array}$ & \multicolumn{2}{|c|}{$\begin{array}{l}\text { It is a kind of integrated technology, which processes various media } \\
\text { information such as text, graphics, image, sound, animation, video, etc. } \\
\text { by means of digital acquisition, digital acquisition, digital compression, } \\
\text { digital decompression, digital editing, digital storage and so on, and then } \\
\text { displays them in a single or composite form. }\end{array}$} & 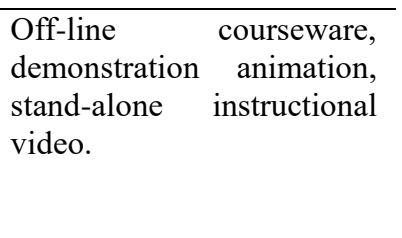 \\
\hline $\begin{array}{l}\text { Internet } \\
\text { technology }\end{array}$ & \multicolumn{2}{|c|}{$\begin{array}{l}\text { A technology that combines communication technology with computer } \\
\text { technology, and it is based on the network protocol and realizes the } \\
\text { sharing of resources and the two-way exchange of information by } \\
\text { connecting independent and scattered computers in the area. }\end{array}$} & $\begin{array}{lr}\text { Network } & \text { courses, online } \\
\text { learning } & \text { systems; for } \\
\text { example: } & \text { National } \\
\text { Education } & \text { Resources } \\
\text { Public Platform, MOOC of } \\
\text { Chinese Universities, etc. }\end{array}$ \\
\hline $\begin{array}{l}\text { Software } \\
\text { development } \\
\text { technology }\end{array}$ & \multicolumn{2}{|c|}{$\begin{array}{l}\text { By writing a programming language and developing a collection of a } \\
\text { series of computer instructions and data organized in a specific order, it } \\
\text { is the embodiment and instantiation of human brain thinking, and it is } \\
\text { the purest artificial digital product. }\end{array}$} & $\begin{array}{l}\text { Calculation software, APP, } \\
\text { etc., such as: mind map, } \\
\text { geometer sketchpad art } \\
\text { board, etc. }\end{array}$ \\
\hline $\begin{array}{l}\text { Virtual reality } \\
\text { technology }\end{array}$ & \multicolumn{2}{|c|}{$\begin{array}{l}\text { Create a 3D environment with real-time 3D computer graphics } \\
\text { generation technology, multi-sensory interactive interface technology } \\
\text { and high-resolution high-speed display technology. This environment } \\
\text { can be either a virtual imagination 3D environment or a real-world 3D } \\
\text { simulation, and it is a space that is both physical and psychological. }\end{array}$} & $\begin{array}{l}\text { Virtual Reality (VR), } \\
\text { Augmented Reality } \\
\begin{array}{l}\text { Mixed Reality } \\
\text { resources. }\end{array}\end{array}$ \\
\hline $\begin{array}{l}\text { Artificial } \\
\text { intelligence } \\
\text { technology }\end{array}$ & \multicolumn{2}{|c|}{$\begin{array}{l}\text { Simulate human and other bio-intelligence behaviors through artificial } \\
\text { neural networks, fuzzy logic, intelligent optimization algorithms, etc., to } \\
\text { make products more adaptive }\end{array}$} & $\begin{array}{l}\text { Intelligent partner, } \\
\text { intelligent tutor, intelligent } \\
\text { guidance system. }\end{array}$ \\
\hline $\begin{array}{l}\text { 4.2. The Con } \\
\text { Resource } \\
\text { It is a complex } \\
\text { resources. With th } \\
\text { technology, unders } \\
\text { relatively fixed per } \\
\text { are also stable, }\end{array}$ & $\begin{array}{l}\text { ass of } 3 D \text { Digital Learning } \\
\text { rocess to recognize digital learning } \\
\text { ontinuous development of information } \\
\text { ding is also advancing. However, in a } \\
\text { l, the types of digital learning resources } \\
\text { the variability of cognition cannot }\end{array}$ & \multicolumn{2}{|c|}{$\begin{array}{l}\text { Compass, also named "compass", "needle disc", is the use of } \\
\text { the principle of the compass by several parallel arrangement, } \\
\text { horizontal rotation of the needle and the azimuth scale of the } \\
\text { disc formed a direction indicator instrument. Each circle on } \\
\text { the disk represents the ancients' understanding of a level of } \\
\text { information in the larger system of the universe. The digital } \\
\text { learning resource compass adopts a 3D model, including } \\
\text { three levels: } 1 \text { core, } 3 \text { acquisition methods and N resource } \\
\text { types, as shown in Figure } 3 \text { : }\end{array}$} \\
\hline
\end{tabular}




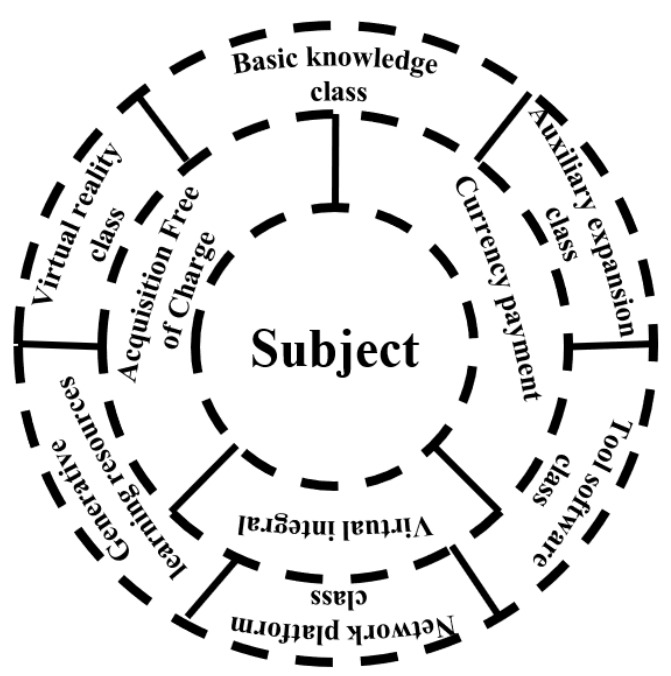

Figure 3 3D digital learning resources compass

"1" core: the most fundamental attribute of digital education resources is the manifestation of knowledge, which needs to undertake three basic tasks: knowledge transmission, skill training and ability cultivation ${ }^{[15]}$. As a subset of digital education resources, digital learning resources also need to carry out these three tasks, and knowledge representation is still the fundamental attribute. The dictionary of education defines a subject as "a system of basic scientific knowledge based on educational objectives, school tasks, length of schooling and the level of development of students at a certain age". It can be seen that the essence of a subject is still a field of knowledge systematically organized for teaching and learning (for example, history, physics, music). Subjects are still the most fundamental difference while classifying the digital learning resources, so subjects are regarded as the innermost layer of the disc. Just as the compass disk can rotate freely horizontally, the academic circle can also rotate horizontally and combine with the data of other disks to form different types of digital learning resources.

The acquisition method of "3" type digital learning resource: There are three ways for users to obtain digital learning resources. First, acquisition without compensation, at present, there are a large number of such resources in the network(for example, national basic education resources public service platform); Second, money payment, that is, to obtain digital learning resources through the purchase method(for example, English quality course of MOOC); Third, the virtual integral, to obtain digital learning resources through the method of integral exchange, and integral can be obtained by doing tasks, digital resource exchange and other methods(for example, material China Network). As shown in Figure 4:

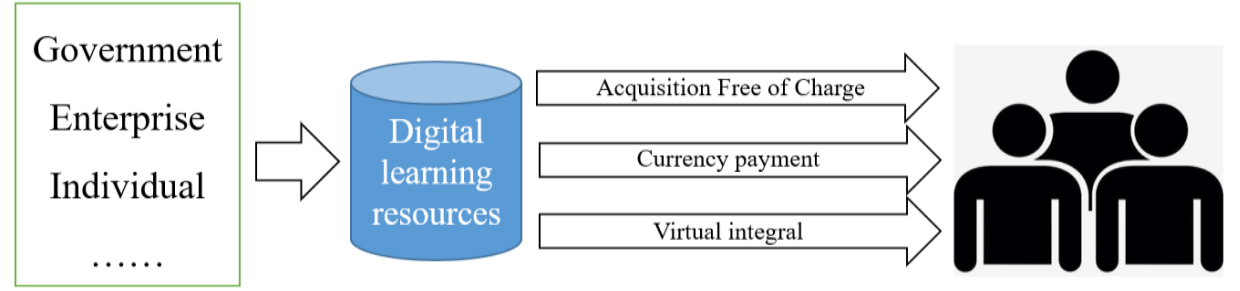

Figure 4 Acquisition of digital learning resources

"N" types of digital learning resources: there are much of classification of digital learning resources, this study mainly cuts into the key dimension of information technology on the digital learning resources development, and digital learning resources can be divided into the following five categories, namely " $\mathrm{N}=5,5$ kinds of resources are: basic knowledge class, auxiliary development class, tools, software class, network platform class, virtual reality class and generative digital class learning resources.

The "circle" of each level of the 3D digital learning resources compass can rotate back and forth, so as to systematically distinguish each kind of resources and combine them into different kinds of learning resources. Different types of digital learning resources can be combined by rotating the disks of three levels. For example, different types of subjects can be selected by rotating the compasses of subject dimensions. Take mathematics as an example, rotate the subject compass to select mathematics; continue to rotate the compass to obtain dimensions, which can combine the mathematics learning resources acquisition free of charge, the mathematics learning resources paid in currency, and the mathematics learning resources exchanged in virtual integral; rotate the digital resource type compass under the perspective of information technology, which can combine the mathematics basic knowledge learning resources acquisition free of charge, and the currency paid mathematics basic knowledge learning resources, mathematics basic knowledge learning resources exchanged by virtual integral, mathematics tool software learning resources acquisition free of charge, mathematics tool software learning resources paid in currency, mathematics tool software learning resources exchanged by virtual integral, etc.

As an element that can stimulate and help learners to learn effectively, learning resources are becoming more and more important. From the Paleolithic, agricultural, industrial, and 
hell: Virtual reality and its implications" [M]. London: Hodder \& Stoughton, 1992.

[15] WANG Zhu-Li. "How does Technology Change Education?_On the Influence of Artificial Intelligence on Education" [J]. E-education research,2018.

\section{REFERENCES}

[1] WILLIAM W, JURSSG. "Research methods in educa tion: an introduction[M]. Boston:Pearson",2005:52.

[2] HE Xiang-Chun, GUO Shao-Qing, ZHANG Jin-Liang. "System Structure and Function Evolution of E-learning Space_-Study on Connotation of e-Learning Space and Development of School Education (2)" [J]. E-education Research, 2017(05):38-44.

[3] Janaszewski, Molenda. "Definition and Evaluation of Educational Technology" [M]. Peking University Press, 2010.

[4] ZHANG Wei-Min. "Learning Resources and Learning Processes - The Main Objects of Educational Technology Practice and Research" [J]. China Educational Technology, 1997(7):12-13.

[5] SHEN Shu-Sheng. "Resources are an extension of the media" [J]. China Educational Technology, 2000(7):13-16.

[6] LI KE-Dong. "Digital Learning (I) - The Core of Information Technology and Curriculum Integration" [J]. E-education Research, 2001(8):46-49.

[7] CAO Mei, ZHANG Zeng-Rong. "The connotation and deepening of learning resources" [J]. China Educational Technology, 2002(4):14-17.

[8] ZHANG Jun-Wei, PENG Ya-Qing. "Construction of System of Learning Resources Evaluation Principle" [J]. Theory and Practice of Education, 2005(8):52-53.

[9] ZHU Zhi-Ting, MENG Qi. "Educational Technology Practicality: A New Discourse Interpreting the Effectiveness of Learning Resources" [J]. E-education Research,2006(4):3-6.

[10] ZHU Zhi-Ting. "Modern Educational Technology: Entering Information Education" [M]. Beijing: Higher Education Press, 2001.

[11] LI Jian-Guo. "Practical Exploration of High-quality Digital Learning Resources Sharing in Colleges and Universities" [J]. Education Exploration, 2009(10):128-130.

[12] LI Shuang. "Distance Education Resources Construction: From Teaching Resources to Learning Resources" [J]. Distance Education in China, 2011(10):70-72.

[13] CHEN Lin, WANG Chu, LI Fan. "Research on Creating Public Learning Mode of Digital Learning Resources" [J]. China Educational Technology, 2012(1):73-77.

[14] Sherman B, Judkins P. "Glimpses of heaven, visions of 